Portland State University

PDXScholar

5-7-1979

\title{
The Effects of Morning and Afternoon Scheduling on the Clinical Performance of Severe Aphasic Adults
}

Judith Ann Fisher

Portland State University

Follow this and additional works at: https://pdxscholar.library.pdx.edu/open_access_etds

Part of the Speech Pathology and Audiology Commons

Let us know how access to this document benefits you.

\section{Recommended Citation}

Fisher, Judith Ann, "The Effects of Morning and Afternoon Scheduling on the Clinical Performance of Severe Aphasic Adults" (1979). Dissertations and Theses. Paper 2787.

https://doi.org/10.15760/etd.2782

This Thesis is brought to you for free and open access. It has been accepted for inclusion in Dissertations and Theses by an authorized administrator of PDXScholar. Please contact us if we can make this document more accessible: pdxscholar@pdx.edu. 
AN ABSTRACT OF THE THESIS OF Judith A. Fisher for the Master of Science in Speech Communication with emphasis in Speech Pathology and Audiology presented May 7, 1979.

Title: The Effects of Morning and Afternoon Scheduling on the Clinical Performance of Severe Aphasic Adults.

APPROVED BY MEMBERS OF THE THESIS COMMITTEE:
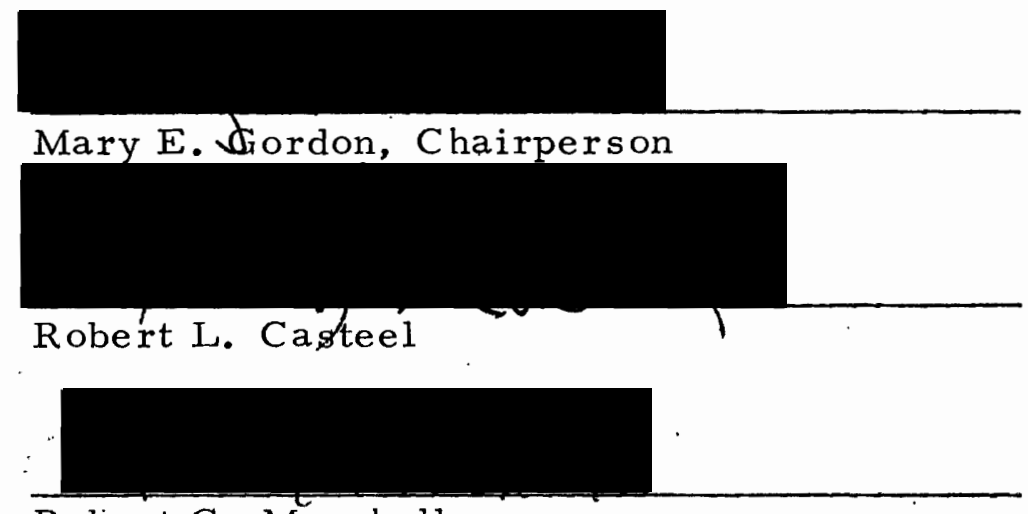

Robert C. Marshall

Concern regarding variables which influence the performance of aphasic adults has been demonstrated in the literature. Marshall et al. (1978) found that one such variable, scheduling of intervention, influenced significantly the test performance of their subjects. They determined that the aphasic subjects performed better in the morning than in the afternoon. The purpose of the present study was to determine if performance of severe aphasic adults on easy and diffi- 
cult, single-word picture-identification tasks, presented in a clinically reinforcing manner, is differentially affected by morning and afternoon scheduling.

The questions posed in this investigation were: 1) Does morning versus afternoon scheduling significantly affect the number of correct responses of severe aphasic adults on clinically presented tasks? and 2) Does morning versus afternoon scheduling have significantly more effect on the number of correct responses made by severe aphasic adults on easy or difficult clinically presented tasks?

To answer these questions ten severe aphasic adults were randomly divided into two groups: five evaluated in the morning first and in the afternoon second, and five evaluated in the afternoon first and the morning second. The evaluation instrument consisted of forty sets of pictures, containing twenty "difficult" sets and twenty "easy" sets randomly distributed throughout the instrument. Each subject responded to the one-word stimuli presented by the experimenter by pointing to the pictures believed to represent the stimuli. The responses were scored as correct or incorrect and also were qualitatively scored using a 6 - point scale with $2-6$ being descriptions of correct responses and 1 being incorrect.

A Treatments-by-Treatments-by-Subjects Design Two Factor Analysis of Variance for Repeated Measures was utilized to 
assess statistically the main effect of scheduling and the interaction of scheduling and task difficulty. The Wilcoxon Matched-Pairs Signed-Ranks Test was used to analyze the qualitative effects of scheduling/task difficulty inte raction.

Both main and interaction effects, quantitatively and qualitatively were determined to be nonsignificant. Possibly the severity level of the subjects and/or the clinical presentation of the tasks explain the discrepancy in results between the present investigation and the Marshall et al. (1978) study. The questions posed in this investigation can be answered: 1) There does not appear to be a significant difference in the effect of morning versus afternoon scheduling on the correct responses of some severe aphasic adults when picture-identification items are presented in a "clinical," rather than "test" manner. 2) There does not appear to be a significantly greater effect in the morning or afternoon on the correct responses of some severe aphasic adults on easy or on difficult picture-identification task items. In addition, there does not appear to be a significant difference in the quality of the responses of severe aphasic adults between easy and difficult items and between morning and afternoon presentation. 
THE EFFECTS OF MORNING AND AFTERNOON SCHEDULING ON THE CLINICAL PERFORMANCE OF SEVERE APHASIC ADULTS

$$
\text { by }
$$

JUDITH ANN FISHER

A thesis submitted in partial fulfillment of the requirements for the degree of

\author{
MASTER OF SCIENCE \\ in \\ SPEECH COMMUNICATION \\ With emphasis in Speech Pathology
}

Portland State University

1979 
TO THE OFFICE OF GRADUATE STUDIES AND RESEARCH:

The members of the Committee approve the thesis of

Judith Ann Fisher presented May 7, 1979.

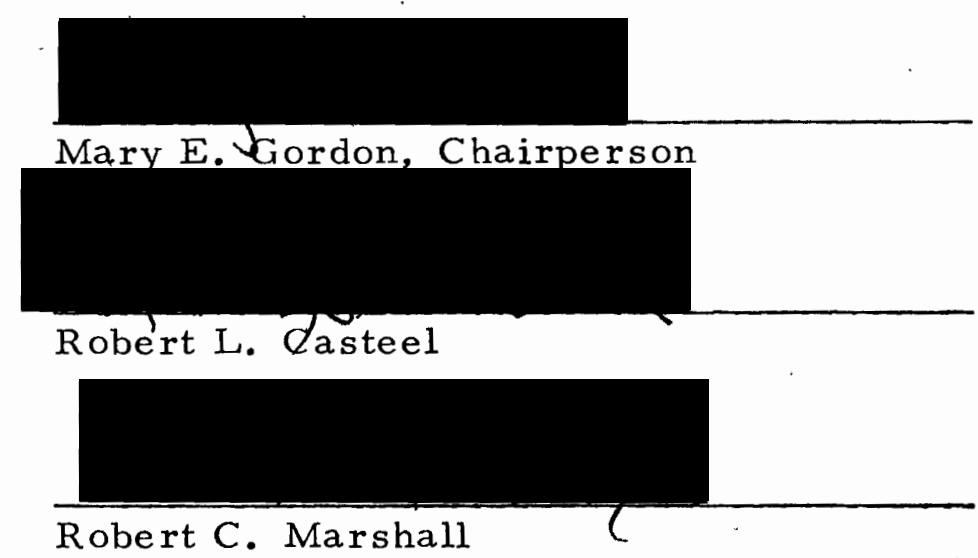

APPROVED:

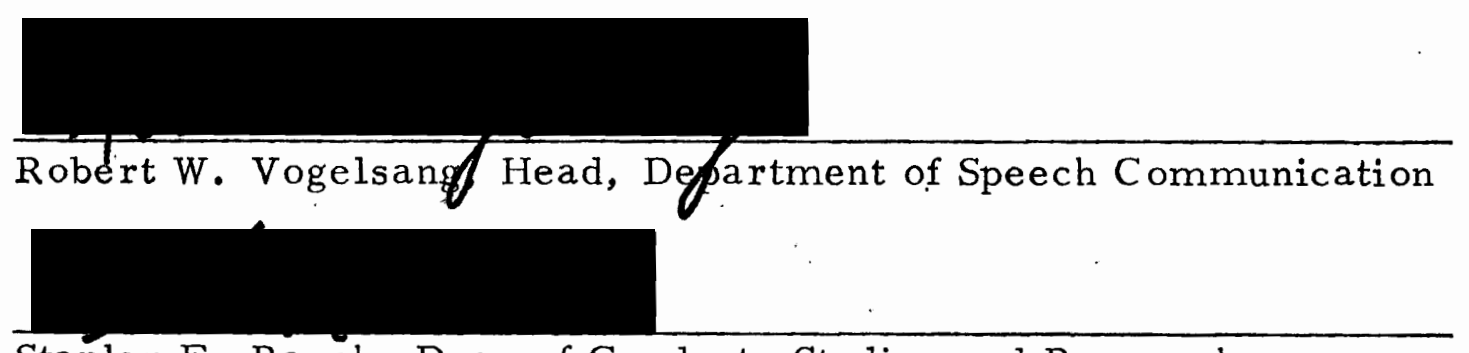

Stanley E. Rauch, Dean of Graduate Studies and Research 


\section{ACKNOWLEDGMENTS}

Thank you, Mary Gordon, for your quality guidance, your subtle encouragement and your warm presence.

Thank you, Dr. Marshall and Dr. Casteel, for your valuable input.

Thank you, Connie Tompkins, for sharing your ideas.

Thank you, Dale, for putting up with so much.

Thank you, Special Friends, for your continual support and encouragement.

I needed you all. 


\section{TABLE OF CONTENTS}

PAGE

ACKNOWLEDGMENTS . . . . . . . . . . . . . . iii

LIST OF TABLES . . . . . . . . . . . . . . v vi

\section{CHAPTER}

I INTRODUCTION AND STATEMENT OF

PURPOSE •................. 1

Introduction ............. 1

Statement of Purpose......... 3

II REVIEW OF THE LITERATURE . . . . . . 4

Variables of Presentation ....... 4

Characteristics of Stimuli

Context of Stimulus Presentation

Rate of Presentation

Scheduling of Presentation

Anxiety/Fatigue............ 13

Scheduling . . . . . . . . . . 16

III METHODS ................ 18

Subjects................ 18

Description

Selection 
CHAPTER

PAGE

Experimental Materials ........ 19

Experimental Procedures ....... 20

Administration

Data Collection

Data Analysis........... 22

IV RESULTS AND DISCUSSION . . . . . . . 23

Results ............... 23

Discussion ............ 26

V CONCLUSIONS AND IMPLICATIONS ..... 32

Summary and Conclusions ...... . 32

Clinical Implications . . . . . . . 34

Implications for Further Research . . . 35

SELECTED BIBLIOGRAPHY . . . . . . . . . . . 37

APPENDIX A . . . . . . . . . . . . . . . 43

Subject Charracteristics

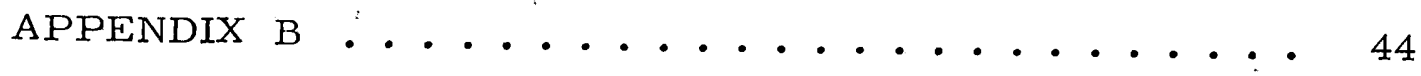

Scoresheet

APPENDIX C . . . . . . . . . . . . . . . . .

Sample Easy and Difficult Items

APPENDIX D . . . . . . . . . . . . . . 46

Raw Scores, Correct/Incorrect

APPENDIX E

Sums of Raw Scores, Qualitative 


\section{LIST OF TABLES}

TABLE

PAGE

I Qualitative Scoring System . . . . . . . 22

II Analysis of Variance of Two Variables:

Scheduling and Difficulty ......... 24

III Wilcoxon Qualitative Analysis of Scheduling

and Difficulty Effects.......... 26 


\section{CHAPTER I}

\section{INTRODUCTION AND STATEMENT OF PURPOSE}

\section{Introduction}

Speech-language pathologists responsible for management of aphasic clients need to be aware of variables which affect their clients' performances. Effectiveness of both diagnostic and management procedures is influenced by a subject's level of functioning at any given time. Fluctuations in performance alter information upon which decisions regarding initiation of treatment, treatment goals, starting proficiency level and termination of treatment are based (Marshall, Tompkins and Phillips, 1978)." Also, logically, aphasic clients accrue greater benefit from intervention when they are performing optimally (Buck, 1968; Eisenson, 1973). Thus, information regarding variables which influence performance of aphasic clients is valuable to clinicians.

The effects of numerous variables involving the actual presentation of stimuli have been researched. Characteristics of stimuli presented, context of stimulus presentation, rate of presentation and format of presentation have been the general focus 
of such research.

A variable believed to influence the performance of aphasic individuals, i.e., scheduling of treatment sessions, has received limited attention in the literature. The frequency of scheduled treatment sessions has been examined on two occasions with conflicting results. Pizzamiglio and Roberts (1967) found that greater frequency of intervention led to greater improvement in performance of their aphasic subjects, while Holland and Sonderman (1974) concluded that frequency of sessions was not significantly related to success of their program.

Concern regarding the effects of fatigue on the performance of aphasic clients prompted research regarding scheduling of management within the daily routine. Marshall and King (1973) found aphasic subjects to perform poorer following physical exercise. Buck (1968) and Marshall et al. (1978) determined that overall communicative performance of aphasic clients was superior during the morning hours than during the afternoon. Marshall et al. tested aphasic subjects in the morning and afternoon, two to four days apart, with a shortened version of the Porch Index of Communicative Ability (PICA) in a structured examination setting. They found their subjects' overall performances to be significantly better in the morning than in the afternoon. While all subtests yielded better results in the morning, only two were significantly better, i.e., a 
verbal naming task and an auditory object identification task.

Due to the importance of variables influencing the performance of aphasic individuals, the concern with fatigue and the limited research on scheduling effects on clinical perfor mance, this investigator desired to expand on the findings of Marshall et al. (1978) by specifically examining effects of scheduling on the clinical (appropriately reinforced) performance of aphasic adults.

\section{Statement of Purpose}

The purpose of this study was to assess the influence of scheduling on the clinical performance of aphasic adults. More specifically, the purpose was to determine if performance of severe aphasic adults on easy and difficult, single-word picture-identification tasks, presented in a clinically-reinforcing manner, is differentially affected by morning and afternoon scheduling.

The questions posed were:

1) Does morning versus afternoon scheduling affect the number of correct responses on clinically presented tasks significantly?

2) Does morning versus afternoon'scheduling have significantly more effect on the number of correct responses on easy or difficult clinically presented tasks? 
CHAPTER II

\section{REVIEW OF THE LITERATURE}

\section{Variables of Presentation}

Identification of variables which affect the performance of aphasic individuals is important to aphasia clinicians in order to promote the success of their clients. The form of stimuli and manner in which stimuli are presented to aphasic clients affects the accuracy of their responses. Researchers have examined the effects of characteristics, contexts, rate and scheduling of stimuli on the performance of aphasic adults. General conclusions of relevant studies are presented below.

\section{Characteristics of Stimuli}

Aphasic clients respond differently to various forms of stimuli. Research has focused on the influence of complexity, length, frequency of usage, stress, realism, and modality of the stimulus on the performance of aphasic subjects.

Complexity. In general, increased complexity of a stimulus results in increased errors by aphasic subjects. Shewàn and Canter (1971) found that greater syntactic complexity increased 
the number of errors made by their subjects. Weidner and Lasky (1976) obtained similar results for grammatic complexity.

Semantic complexity (in terms of level of abstraction) was determined by Siegel (1959) to function differently. Siegel used words categorized into high, medium and low abstraction levels in a study by Darley, Sherman and Siegel (1959). Some examples of the three levels include the words: DIG (low), ARRANGE (medium), and BECOME (high). Siegel (1959) found more errors were made on words of both high and low abstraction levels than on those of medium abstraction level.

Length. Siegel (1959), as well as. Filby, Edwards, and Seacat (1963) and Bricker, Schuell and Jenkins (1964), found that aphasic subjects make more errors on long stimulus words than on short stimulus words. Personal accounts of aphasic individuals, as reported by Rolnick and Hoops (1969), suggest shorter sentences are easier to comprehend than longer sentences. Findings of Weigel-Crump and Koenigsknecht (1973) and Weidner and Lasky (1976) supported these suggestions. In an investigation by Shewan and Canter (1971), however, sentence length was determined to have no effect on performance without a simultaneous increase in complexity.

Frequency of Usage. According to Siegel (1959), Schuell, Jenkins and Landis (196I) and Bricker et al. (1964), words of 
greater frequency of occurrence result in fewer errors by aphasic subjects. Conflicting findings of Filby et al. (1963) and WeigelCrump and Koenigsknecht (1973), however, showed that frequency does not significantly alter correctness of responses.

Stress. Variations of vocal stress patterns failed to supply cues for language comprehension to aphasic subjects in a study by Blumstein and Goodglass (1972). In a later study, Goodglass (1973) concluded that "salient" words (important, stressed words) can be used successfully by aphasic individuals to initiate speech. Modality. Goodglass, Barton and Kaplan (1968) compared the performances of aphasic subjects on naming tasks using tactile, olfactory, auditory and visual stimuli. The subjects were presented with objects (such as a spoon and pencil) for tactile stimulation, vials containing common household odors (such as coffee and gasoline) for olfactory stimulation, tape recorded sounds (such as hammering and typewriting) for auditory stimulation, and color photographs of objects for visual stimulation. They found no significant difference in results among the modalities. Dealing with another aspect of modality, Green and Boller (1974) discovered that live presentation of stimuli promotes better performance than does tape-recorded presentation.

Realism. The visual modality has been studied separately in terms of realism of the stimulus. Bisiach (1966) found aphasic 
subjects identified realistic pictures most accurately, line drawings with moderate accuracy, and mutilated pictures least accurately. He concluded that realism provides redundant information which aids in identification. Findings of Benton, Smith and Lang (1972) and Corlew and Nation (1975) failed to support Bisiach's theory when comparing real objects with pictures. A greater number of correct answers occurred in response to objects; however, the difference was not statistically significant in the study of Corlew and Nation. Although the results were slightly statistically significant in the study of Benton et al., they concluded their findings were not clinically significant.

\section{Context of Stimulus Presentation}

Aphasic clients respond differently according to the context within which stimuli are presented. Similarity of stimuli, cues, and noise are variables of context which have been studied.

$$
\text { Similarity of Stimuli. Consensus indicates semantically }
$$

similar words are more difficult to discriminate than semantically unrelated words (Pizzamiglio and Appicciafuoco, 1971; Schuell, 1974; Podroza and Darley, 1977). However, when the task is identification rather than discrimination, semantic redundancy (e.g., "The cat is furry" as opposed to "the cat is nice") and presentation of associated words (words which are logically related) prove to be 
helpful (Wiig and Globus, 1971; Gardner, Albert and Weintraub, 1975). Similarly, Weigl (1968), and Weigl and Bierswisch (1973) found that presentation of the target word or an associated word through an intact modality as a preview of the target word was effective in "deblocking" (permitting) the retrieval of the target word. Both of these latter methods are similar to the technique of prompting or cuing.

Cues. McDearmon and Potter (1975) described a prompt as a representation of the concept involved in the desired response. Although they did not specifically collect data, they indicated that providing simultaneous presentation of stimuli in two modalities, then fading the prompt modality, facilitates appropriate responses. Holland and Sonderman (1974) discovered the same kind of trend using written cues when an auditory stimulus was unsuccessful in eliciting a correct response on its own.

Another form of cuing is termed "alerter," which is a statement used to introduce stimuli. "Alerters" were provided aphasic subjects in studies by Marshall and Thistlethwaite (1977), and Green and Boller (1974). In both cases the "alerters" improved the responses of the subjects.

Green and Boller (1974) studied wording of questions (yes/no, information and commands) as related to the performance of aphasic subjects. They evaluated the responses in terms of correctness 
(a correct response made in the appropriate mode, e.g., saying no to a yes/no question requiring a 'no' response), appropriateness (an incorrect response made in the appropriate mode, e.g. , responding yes to a yes/no question requiring a 'no' response), and inadequacy (an incorrect response made in the wrong mode, e.g., pointing to the floor in response to a yes/no question requiring a 'no' response) of the response. They found wording did not affect correctness of responses, but did improve the appropriateness of the responses. Barton, Maruszewski and Urrea (1969) determined that identification of pictures was easiest in response to open-ended questions; whereas, picture-naming was more difficult; finally, naming in response to a definition or description was the most difficult. Similarly, Podroza and Darley (1977) found open-ended sentences to facilitate naming responses. They also found providing phonetic cues and a set of three words that included the desired word, helped retrieval of names.

Noise. Birch (1956) provided binaural auditory stimulation consisting of a pure tone to aphasic subjects during administration of a task. He found that his subjects' performances improved on the task during this stimulation. Others who have replicated the procedure found contradictory results (Weinstein, 1959; Schuell, Jenkins and Jimēnez-Pabōn, 1964; Siegenthaler and Goldstein, 1967; Wertz and Porch, 1970). Wertz and Porch (1970) did find 
noise stimulation during task administration to reduce latency of responses.

\section{Rate of Presentation}

Aphasic subjects respond differently according to the rate at which stimuli are presented to them. Ebbin and Edwards (1967) indicate the influence of rate is highly individual and should be assessed for each aphasic client independently. Most other researchers found rate of presentation of stimuli to affect performance of aphasic subjects significantly as presented below.

Reduced Rate. Albert and Bear (1974) found that when they slowed the rate of stimulus presentation by $1 / 3$ or more the comprehension of their aphasic subject improved significantly. Brookshire (1971a) noted gradual improvement in naming ability as the interval during which the stimulus was presented grew longer. Weidner and Lasky (1976) compared responses to tape-recorded messages reproduced at reduced and accelerated speeds and concluded that slowing the rate of presentation of continuous speech helps reduce errors of aphasic clients, particularly for less severe aphasic clients. Sheehan, Aseltine and Edwards (1973) found age to be an influencing factor. A younger group ( 50 years and below) improved their performance significantly when spoken words were slowed by interpolated silence (i.e., surrounding each phoneme in 
a word with $150 \mathrm{msec}$. of silence), while the older group failed to improve.

Another method of slowing speech, that of pause insertion, was studied by Liles and Brookshire (1975). They determined that pauses which break messages into two or fewer pieces of information result in a significant difference in performance: Others who have established that slowed rate of presentation improves performance of aphasic subjects include Weigel-Crump and Koenigsknecht (1973), Gardner et al. (1975) and Cermak and Moreines (1976). Rolnick and Hoops (1969) indicated aphasic individuals themselves request that people talk more slowly to them.

\section{Latency of Response. Results of a study by Swinney and}

Taylor (1971) indicated that latencies in responses of aphasic subjects are greater than those of normal subjects on short term memory recognition tasks. The "shutter" principle proposed by Wepman (1972) is his explanation for this latency in responding characteristic of aphasic individuals. He suggested the mind "opens" for stimulation, then "closes out" further stimulation until the initial information has been processed. In the case of aphasic persons, the processing time is longer than for non-aphasic persons and a slowed pace is therefore desirable.

Ebbin and Edwards (1967) derived less conclusive evidence from their study and concluded that the effects of rate of presentation 
on performance of aphasic clients is highly individual and needs to be assessed independently for each client.

\section{Scheduling of Presentation}

Aphasic subjects respond differently to different schedules of stimuli presentation. Variables of scheduling include amount, order and frequency of presentation of stimuli.

Amount. Schuell (1953a, 1954, 1974) has continually emphasized the need for abundant auditory stimulation in the treatment of aphasic clients. Findings of Weigel-Crump and Koenigsknecht (1973) supported Schuell's contention. They determined that word retrieval skills of words drilled during management improved significantly over words not drilled during management procedures. Helmick and Wipplinger (1975) found stimulus repetition to result in improved naming skills; however, large amounts of stimulus repetition did not improve naming skills more than did small amounts.

Order of Complexity. According to Toubbeh (1969) Brookshire (1972) and Brookshire and Lommel (1974), stimuli need to be presented in an order which reduces the incidence of failure. Toubbeh found lack of success resulted in increased errors and trial-anderror responses. Both Brookshire and Brookshire and Lommel discovered a disruption in performance of their aphasic subjects 
following difficulty or failure on task items. Brookshire concluded that progression of testing should be ordered from easy to difficult. From their study, Engmann and Brookshire (1970) determined a need to order visual task items from simple to increasingly complex.

Frequency of Sessions. As indicated in the introduction, there is conflicting information regarding the influence of frequency with which treatment sessions are held. For instance, Pizzamiglio and Roberts (1967) found their subjects improved significantly faster with daily intervention than with only alternate day sessions. Conversely, Holland and Sonderman (1974) determined that the frequency of treatment sessions was not significantly related to success of the program.

The variables discussed thus far are under direct control of the clinician. They include the character of the stimuli and the context, rate and scheduling of stimuli presentation. A less directly controllable factor, fatigue/anxiety, may also influence the performance of aphasic individuals.

\section{Anxiety/Fatigue}

Concern with the effects of fatigue on the communicative ability of aphasic individuals has been indicated in aphasiology literature over a number of years (Goldstein, 1948; Martin, 1962; 
Buck, 1968; Toubbeh, 1969; Eisenson, 1973; Jenkins, Jiménez- . Pabón; Shaw and Sefer, 1975). It is generally agreed increased fatiguability accompanies brain damage as a physiological concomitant due to the organism's coping with the environment with reduced ability (Goldstein, 1948; Buck, 1968; Eisenson, 1973; Marshall et al., 1978). Buck indicates fatigue reduces the amount of benefit that can be derived from clinical intervention. In order to investigate this contention, Marshall and King (1973) studied the effects of physical exercise on performance of sixteen aphasic subjects. They found communicative performance, as revealed by overall PICA scores, deteriorated as a result of fatigue caused by isokinetic exercise designed to simulate the amount of fatigue created by a physical therapy session. They suggested a need to provide language intervention before physical exercise.

Some believe anxiety is the cause of much of the fatigue experienced by aphasic persons. For instance, Goldstein (1948) indicated aphasic individuals are distressed more often because of their inability to cope with ordinary tasks. He suggested fatigue is the manifestation of distress. Similarly, Buck (1968) described incapacitating fatigue as the result of excessive pressure. More recently, Marshall and Watts (1976) found relaxation procedures to aid performance of aphasic subjects on PICA verbal tasks. They proposed the improvement following relaxation was due to the 
reduction of anxiety.

According to both Goldstein (1948) and Buck (1968), shorter sessions have been the usual approach employed by clinicians to combat fatigue. However, both suggested reduction of stress / pressure as a more efficient method of dealing with the problem. In the clinical setting, this may mean maintaining a high success response ratio. The more tasks a client can do, the less stressed and less fatigued the client will be (Goldstein, 1948).

Brookshire's (1972 and 1976) findings support the need for a high rate of success. His aphasic subjects used more errors on easy items following difficult items and fewer errors on difficult items following easy items for both naming and direction-following tasks. Brookshire speculated their failures created emotional responses which interfered with their subsequent performance. Eisenson (1973) distinguished between fatigue, stress and anxiety, stating that any one of these factors might interfere with performance of aphasic individuals. He suggested reduction of stress or rest periods as solutions. It is difficult to determine if fatigue and anxiety are separate or if one causes the other. Most importantly, their disruptive effect on communicative performance of aphasic individuals is known and means of reducing this effect is being researched: Shorter sessions and higher success ratios have been investigated and encouraged. Scheduling of treatment sessions 
early in the day, before patients have time to become fatigued or anxious, has been a clinically accepted approach, but has received only limited research attention.

\section{Scheduling}

Buck (1968) investigated the effects of time of day on the performance of aphasic individuals. He reported a case study of an aphasic patient in which the patient was tested three times a day for a period of ten days. Identical intellectual tests were used to test the patient in the morning, in the mid-afternoon after a two-hour period of bed rest, and in the late afternoon preceded by no bed rest. No language intervention, physical the rapy or occupational the rapy was provided during the ten-day period. Buck found the morning scores significantly exceeded both the mid-and late-afternoon scores; the mid-afternoon scores significantly surpassed the late afternoon scores. He concluded that intervention should be provided aphasic patients in the morning and prior to physical therapy. As noted earlier in this paper, the findings of Marshall and King (1973) support Buck's suggestion to schedule language intervention before physical therapy.

Marshall et al. (1978) researched the effects of morning and afternoon schedúling on the communicative performance of sixteen aphasic subjects. A shortened version of the PICA was administered 
to each subject both in the morning and afternoon, from two to four days apart. Half were tested in the morning first and half in the afternoon first. The subjects were found to perform significantly better overall in the morning than in the afternoon. However, performance on only two of the eleven individual subtests was significantly influenced by scheduling. These were subtest IV, a verbal task requiring the naming of objects and subtest VI, an auditory task requiring the identification of objects by their function. All other subtest scores were higher for morning administration, although not significantly so. The authors concluded that language intervention and evaluation should occur during the morning hours while aphasic persons are functioning optimally.

Since intervention generally occurs in less structured settings than those maintained during formal testing, there is a need to determine if these findings are applicable to the clinical setting as well. 
CHAPTER III

\section{METHODS}

$\underline{\text { Subjects }}$

$\underline{\text { Description }}$

This study involved ten subjects selected from the Portland Veterans Administration Hospital, Visiting Nurses Association, Associated Home Health Service, Rehabilitation Institute of Oregon, Emmanual Hospital, all located in Portland, Oregon, and King City Convalescent Center in King City, Oregon. All subjects had experienced thromboembolic cerebrovascular accidents resulting in dominant hemisphere damage. They were within the first year post onset of aphasia at the time of sampling. Eight of the subjects were male, two were female. Their ages ranged from 55 to 78 years (see Appendix A).

The subjects manifested severe aphasia. Severity was determined by each subject's most recent Porch Index of Communicative Ability (PICA) score on which each had an overall mean score of ten or below (Porch 1973). The PICA consists of eighteen subtests; four verbal, eight gestural and six graphic. Responses are scored 
on a complex. sixteen-point scale. The requirement of forty hours of prior training with the test and its scoring system provides high interscorer reliability of test results. PICA scores were, therefore, considered to be appropriate means of determining severity.

\section{Selection}

Each subject had an estimated Speech Reception Threshold (SRT) determined by the Carhart (1971) method: of at least $40 \mathrm{~dB}$ in the better ear unaided. The SRT was found by averaging pure tone thresholds for the frequencies of 500 and $1000 \mathrm{~Hz}$ and subtracting $2 \mathrm{~dB}$. Each demonstrated normal visual matching ability on a five-item picture matching task.

Prior to the experimental task, each subject demonstrated understanding of the task by pointing to one picture in response to each sample item. This procedure screened out those unable to perform the experimental task and trained the subjects to perform the task, a procedure suggested by Schuell (1953b). . .

\section{Experimental Materials}

The materials used to evaluate the performance of the subjects were selected from the Clinician Controlled Auditory Stimulation for Aphasic Adults (Marshall, 1978). The stimuli consisted of forty sets of pictures with six pictures in a set. One 
picture in each set represented the one-word auditory stimulus provided by the experimenter simultaneously with each set. There were twenty easy (E) picture groups containing words with no semantic relationship. Members within each of twenty difficult (D) groups were all semantically related.

The division between easy and difficult was made by increasing the number of semantic distractors from which the subject selected a response. This method is based on Schuell's (1974) findings that aphasic individuals have a tendency to ". . confuse words that are closely associated in meaning or experience.". Examples of $E$ and D items are provided in Appendix B. The two categories of clinical tasks were randomly distributed throughout the evaluation instrument.

\section{Experimental Procedures}

\section{Administration}

Each subject was evaluated with the evaluation instrument once in the morning, with the session beginning between 9:00 and 10:00 and once in the afternoon, beginning between 3:00 and 4:00. No less than two days and no more than six days lapsed between the two samplings. Order of the two samplings was randomly assigned to the subjects, with one-half evaluated in the morning first

(Group 1) and the other half in the afternoon first (Group 2). Each 
subject served as his/her own control.

Samplings were taken in a clinic room in the care center housing the subject or in a quiet room in the subject's home. The setting approximated a standard clinical session including clinically supportive responses by the experimenter. Hearing and visual screening and the pre-sampling were administered just prior to the experimental procedure (Appendix C).

\section{Data Collection}

Each subject responded by pointing to the pictures he/she believed represents the one-word stimuli presented. Each response was scored as correct or incorrect. Additionally, for an estimation of qualitative appraisal of responses, a $1-6$ rating scale was utilized to score the responses. The qualitative scoring system is presented in Table I.

Repetition of the stimulus alone was provided before both the instructions and stimulus were repeated. Once an inaccurate response occurred, unless immediately corrected, it was scored as inaccurate and the next item was presented. Stimuli and instructions were repeated only when the subject requested them or made no response. A 'no' response, after both instructions and stimuli were repeated, was scored one.

The experimenter administered the items to each subject 
and is certified in the use of the PICA scoring system and had worked with aphasic patients in a clinical practicum for three months prior to initiating this research project.

\section{TABLE I}

\section{QUALITATIVE SCORING SYSTEM}

\begin{tabular}{c|l}
\hline Score & Response Characteristics \\
\hline 6 & Accurate, prompt \\
5 & Accurate, delayed \\
4 & Accurate, self-corrected \\
3 & Accurate, repeated stimulus \\
2 & Accurate, repeated stimulus and instructions \\
1 & Inaccurate \\
\hline
\end{tabular}

\section{Data Analysis}

A Two-Factor Analysis of Variance for Repeated Measures using a Treatments-by-Treatments-by-Subjects Design (Bruning and Kintz, 1968) was applied to correct/incorrect data. The factors analyzed included scheduling (morning and afternoon) and difficulty level (easy and difficult). Both main effects of, and interaction between, these variables were examined. The Wilcoxon Matched-Pairs Signed-Ranks Test (Siegel, 1956) was used to determine the significance of morning and afternoon scheduling relative to qualitative aspects of responses, i.e., the $1-6$ scoring system. 


\section{CHAPTER IV \\ RESULTS AND DISCUSSION}

\section{$\underline{\text { Results }}$}

The purpose of this study was to determine if the clinical performance of severe aphasic adults on easy and difficult task items is differentially affected by morning and afternoon scheduling. Each of the ten subjects identified, by pointing, forty pictures of items named by the experimenter on two separate occasions, once in the morning and once in the afternoon. Each response was scored as correct or incorrect for quantitative analysis. Additionally, each response was qualitatively scored on a $1-6$ point scale with scores of 2-6 representing various levels of correct responses and a score of 1 indicating an incorrect response. Appendix D shows the number of correct responses each subject obtained in the morning and afternoon on easy and difficult items. Appendix $E$ includes the qualitative scores obtained by each subject relative to scheduling and difficulty variables.

The correct/incorrect raw scores were submitted to a Two-Factor Analysis of Variance for Repeated Measures using a 
Treatments-by-Treatments-by-Subjects Design (Bruning and Kintz, 1968). The Wilcoxon Matched-Pairs Signed-Ranks Test (Siegel, 1956) was applied to the qualitative data. Preliminary to reporting the actual results, it should be noted that the distinction made in this study between easy and difficult items was statistically significant beyond the .001 level of significance (Table II).

TABLE II

ANALYSIS OF VARIANCE OF TWO VARIABLES

SCHEDULING AND DIFFICULTY

\begin{tabular}{l|r|r|r|r|r}
\hline \multicolumn{1}{c|}{ Source } & $\begin{array}{r}\text { Sums of } \\
\text { Squares }\end{array}$ & df & $\begin{array}{r}\text { Mean } \\
\text { Squares }\end{array}$ & $F$ & $p$ \\
\hline Subjects & 548.60 & .9 & - & - & - \\
Scheduling & 1.60 & 1 & 1.60 & 1.263 & $>.05$ \\
Difficulty & 144.40 & 1 & 144.40 & 37.565 & $<.001$ \\
Difficulty X Scheduling & 1.60 & 1 & 1.60 & .567 & $>.05$ \\
\hline \multicolumn{1}{c|}{ TOTAL } & 767.60 & 39 & - & - & - \\
\hline
\end{tabular}

The first question posed in this investigation was: does morning and afternoon scheduling significantly affect the number of correct responses on clinically presented tasks? Results of the analysis of variance indicated that effects of scheduling were nonsignificant at the .05 level of significance (Table II). Application of the Wilcoxon Matched-Pairs Signed-Ranks Test (Siege1, 1956) 
revealed that scheduling also failed to significantly affect the qualitative aspects of the subjects' responses at the .05 level of significance.

The second question posed was: does morning versus afternoon scheduling have significantly more effect on the number of correct responses on easy or difficult clinical tasks? The effects of scheduling and task difficulty did not interact to a significant degree at the :05 level of significance, according to the analysis of variance (Table II). Again, analysis of the qualitative aspects of the subjects' responses on the Wilcoxon mirrored the correct/incorrect analysis and were nonsignificant at the .05 level of significance.

Table II contains a summary of the analysis of variance data showing the lack of significance of the affects of scheduling $(F=1.263 ; d f=1 ; p>.05)$ and the interaction of scheduling with task difficulty $(F=.567 ; \mathrm{df}=1 ; \mathrm{p}>.05)$. Table III summarizes the non-parametric analysis of the qualitative information with the Wilcoxon showing lack of significance of scheduling regardless of task difficulty $(T=20.5 ; p\rangle .05)$ on easy items $(T=18.5 ; p>.05)$ and on difficult items $(T=10.0 ; p>05)$. 
WILCOXON QUALITATIVE ANALYSIS OF SCHEDULING AND DIFFICULTY EFFECTS

\begin{tabular}{|c|c|c|}
\hline Source & $\mathrm{T}$ & $\mathrm{p}$ \\
\hline $\begin{array}{c}\text { Total Qualitative } \\
\text { (Scheduling) }\end{array}$ & 20.5 & $>.05$ \\
\hline $\begin{array}{r}\text { Easy Items Qualitative } \\
\text { (Easy X Scheduling) }\end{array}$ & 18.5 & $>.05$ \\
\hline $\begin{array}{r}\text { Difficult Items Qualitative } \\
\text { (Difficult X Scheduling) }\end{array}$ & 10.0 & $>.05$ \\
\hline
\end{tabular}

\section{Discussion}

Results of this investigation indicated there was no significant difference between the performances of the subjects during the morning and the afternoon, on easy or difficult items, either quantitatively or qualitatively. There are two possible interpretations of these findings. The first is that the evaluation procedure or instrument was inadequate to reveal variations in behavior. One possible explanation is that the small number of subjects could have allowed variations from the norm of a few subjects to influence disproportionately the group results. In this case, however, only one subject's (Subject E) total scores for morning and afternoon varied from each other by more than two 
points. This'suggests the nonsignificant group results do reflect the performance of most $(9 / 10)$ of the subjects (refer to raw data in Appendix D).

Another possible explanation is that the evaluation instrument was inadequate. The task may have been too easy to show significant variations for some of the subjects. For instance, looking at the raw data in Appendix D, it can be seen that four of the subjects (A, B, F, and I) scored $38 / 40$ on at least one administration of the task. This means that only two task items remained on which they could perform better during the other administration which reflects a no better than chance variation. Further, it can be seen the scores of these four subjects varied less between the easy and difficult items than did those of the other subjects suggesting the distinction made between easy and difficult items was less applicable to the se subjects than for the others, even though the distinction was shown by this investigation to be statistically significant overall (see Table II). In other words, the instrument itself may have lacked the ability to discriminate adequately variations in performance for all ten subjects.

In addition, the evaluation instrument utilized in the present study required less time to administer (approximately 10 to 20 minutes) than is involved in a normal treatment session (45 to 50 minutes). As a consequence, the resulting data might not reflect 
instances of decline in performance which may occur during one period of the day more than another under normal clinical conditions. Therefore, the brevity of the instrument may have limited its ability to measure all the changes in performance which might occur during a regular clinical session.

A second possible interpretation of the nonsignificant results is that no difference exists in the effects of morning and afternoon scheduling of clinical tasks for severe aphasic adults.. This does not support the widely held clinical belief that aphasic patients perform better in the morning than in the afternoon. Since Marshall et al. (1978) found scheduling to affect the performance of aphasic subjects significantly, the variables which are not consistent between the studies need to be considered individually.

One major difference between the Marshall study and the present study involves the structure of the evaluation setting. While the Marshall study utilized a shortened version of the PICA administered under standard testing conditions, the present study approximated a clinical setting in which the experimenter supplied reinforcing statements according to the perceived needs of each individual subject. It seems likely that if a subject appeared to need more encouragement on one occasion than on another, e.g., in the afternoon more than in the morning, the experimenter responded by increasing the amount of reinforcing statements. If, as indicated 
by Stoicheff (1960) and Brookshire (1971b), encouraging statements do positively affect the performance of aphasic subjects, then some of the negative effects of afternoon scheduling might be counterbalanced by use of such statements. Thus, clinical procedures may be less affected by scheduling variables than standard test procedures.

Another major difference between the Marshall et al. (1978) study and the present investigation involves the severity level of the subjects. In the Marshall study, severity was not directly controlled; however, damage was limited to that which resulted from a single dominant hemisphere cerebrovascular accident. Also, comparing the overall PICA score means, resulting from the shortened version of the PICA, of the subjects in the Marshall study (morning $\bar{X}=12.25$, afternoon $\bar{X}=11.91$ ) with the overall PICA score mean of the subjects in the present study $(\bar{X}=8.18)$ reveals the generally higher level of functioning of the subjects in the Marshall study. Marshall et al. (1978) found scheduling to influence significantly the performance of their subjects. The present study included aphasic individuals who had experienced more than one "stroke" and did not control for the extent of the damage. As a result, some of the subjects may have been so linguistically limited that even when they were performing optimally they made many errors. As indicated earlier, Brookshire (1972) found that, in 
aphasic subjects, errors generate errors and concluded, ". . failures may generate emotional responses which are themselves capable of disrupting the patient's performance." This suggests that the amount of variability in performance of the subjects for whom the task was difficult may have been limited by the difficulty of the task and the subjects' reactions to their errors.

Further, the type of cerebral damage was not controlled in this study. Severity was determined with PICA scores alone. Low overall PICA scores are often earned by aphasic clients whose expression is limited by motoric rather than auditory dysfunction. As a result, some of the subjects in the present investigation performed much better than others on the word-identification tasks despite their similar PICA scores. With this kind of uncontrolled variability in ability, it is difficult to measure accurately performance changes of all the subjects with a single task evaluation instrument. In other words, the lack of control of the type of cerebral damage may have rendered the instrument ineffective. Secondarily, this investigation was designed to determine whether there were qualitative differences in the responses of the subjects relative to the scheduling and task difficulty. The results indicate there were no significant differences qualitatively relative to either level of difficulty in terms of scheduling (see Table III). Interpretation of the se findings follow the same reasoning as the 
quantitative findings. However, qualitative judgments are subjective and the refore more likely to reflect bias. The fact that they a re nonsignificant, just as the objective results, suggests their validity in this case. Thus, both the quantitative and qualitative results of this study suggest scheduling may not be an important variable to consider in the treatment of some severe aphasic clients with picture-identification tasks. 


\section{CHAPTER V}

\section{CONCLUSIONS AND IMPLICATIONS}

\section{Summary and Conclusions}

Concern regarding variables which influence the performance of aphasic adults has been demonstrated in the literature. Marshall et al. (1978) found that one such variable, scheduling of intervention, influenced significantly the test performance of their subjects. They determined that the aphasic subjects performed better in the morning than in the afternoon. The purpose of the present study was to determine if performance of severe aphasic adults on easy and difficult, single-word picture-identification tasks, presented in a clinically reinforcing manner, is differentially affected by morning and afternoon scheduling.

The questions posed in this investigation were: 1) Does morning versus afternoon scheduling significantly affect the number of correct responses of severe aphasic adults on clinically presented tasks? and 2) Does morning versus afternoon scheduling have significantly more effect on the number of correct responses made by severe aphasic adults on easy or difficult clinically presented 
tasks?

To answer these questions ten severe aphasic adults were randomly divided into two groups, five evaluated in the morning first and in the afternoon second, and five evaluated in the afternoon first and the morning second. The evaluation instrument consisted of forty sets of pictures, containing twenty "difficult" sets and twenty "easy" sets randomly distributed throughout the instrument. Each subject responded to the one-word stimuli presented by the experimente $r$ by pointing to the pictures believed to represent the stimuli. The responses, were scored as correct or incorrect and also were qualitatively scored using a 6 - point scale with $2-6$ being descriptions of correct responses and 1 being incorrect.

A Treatments-by-Treatments-by-Subjects Design Two Factor Analysis of Variance for Repeated Measures was utilized to assess statistically the main effect of scheduling and the interaction of scheduling and task difficulty. The Wilcoxon Matched-Pairs Signed-Ranks Test was used to analyze the qualitative effects of scheduling and scheduling/task difficulty interaction.

Both main and interaction effects, quantitatively and qualitatively were determined to be nonsignificant. Possibly the severity level of the subjects and/or the clinical presentation of the tasks explain the discrepancy in results between the present investigation and the Marshall et al. (1978) study. The questions 
posed in this investigation can be answered: 1) There does not appear to be a significant difference in the effect of morning versus afternoon scheduling on the correct responses of some severe aphasic adults when picture-identification items are presented in a "clinical," rather than a "test" manner. 2) There does not appear to be a significantly greater effect in the morning or afternoon on the correct responses of some severe aphasic adults on easy or on difficult picture-identification task items. In addition, there does not appear to be a significant difference in the quality of the responses of severe aphasic adults between easy and difficult items and between morning and afternoon presentation.

\section{Clinical Implications}

Two implications from this investigation may be valuable clinically. First, if there is no difference in the performance of severe aphasic subjects between morning and afternoon on clinically presented tasks, while there is a significant difference for less severely impaired individuals, then clinical intervention perhaps should be scheduled accordingly. The severe clients could be scheduled in the afternoon to leave the mornings available for the less severe clients who perform optimally at that time. It should be cautioned that the results must not be generalized to test situations for severe aphasic clients. It may be that even severe 
aphasic clients should be tested in the morning, but may receive equal benefit from either morning or afternoon scheduling of management. Similarly, it may be that less severe clients perform equally as well in the morning and afternoon on clinical as opposed to test-type tasks.

Secondly, if the positive encouragement available in the clinical presentation of tasks overshadows the effects of scheduling on the performance of severe aphasic adults, then scheduling may be a less important variable to consider than providing reinforcement. This also may be true for less severely impaired clients. These findings suggest scheduling may be a less important consideration with severe aphasic adults than less severe aphasic adults and with reinforcing conditions than non-reinforcing conditions.

\section{Implications for Further Research}

If this investigation were to be replicated, or if further research in this area were to be explored, the following suggestions might aid the researcher: 1) Either the type of aphasia should be controlled to ensure homogeneity of the subjects and thereby enable one evaluation instrument to be an equally effective measuring device with all the subjects, or a variety of tasks, appropriate to the variability in subjects, should be utilized. 
2) The task should be sufficiently difficult, i.e., sensitive, to allow large enough variations for differences in performance to be visible. If this study were to be expanded upon, other researchers might compare the effects of scheduling on the performance of aphasic adults at various levels of severity, under both clinically reinforcing and standard test conditions. Evaluation of the effects of scheduling at different periods in the recovery of aphasic patients might also provide useful information for aphasia clinicians. 
ALBERT, M. L. and BEAR, D. Time to understand: a case study of word deafness with reference to the role of time in auditory comprehension. Brain, 97:337-84, 1974 .

BARTON, M., MARUSZEWSKI, M. and URREA, D. Variation of stimulus context and its effect. on word-finding ability in aphasics. Cortex, 5:351-65, 1969.

BENTON, A. L., SMITH, K. C. and LANG, M. Stimulus characteristics and object naming in aphasic patients. J. Com. Dis., 5:19-24, 1972.

BIRCH, H. G. Experimental investigations in expressive aphasia. N. Y. State J. Med., 56:3849-52, 1956.

BISIACH, E. Perceptual factors in the pathogenesis of anomia. Cortex, 2:90-5, 1966.

BLUMSTEIN, S. and GOODGLASS, H. The perception of stress as a semantic cue in aphasia. JSHR, 15:800-06, 1972.

BRICKER, A. L., SCHUELL, H. and JENKINS, J. J. Effects of word length and word frequency on aphasic spelling errors. JSHR, 7:183-93, 1964.

BROOKSHIRE, R. H. Effects of trial time and inter-trial interval on naming by aphasic subjects. J.Com. Dis., 3:289-301, $1971 \mathrm{a}$.

- Effects of delay of reinforcement on probability learning by aphasic subjects. JSHR, 14:92-105, 1971b.

- Effects of task difficulty on the naming performance of aphasic subjects. JSHR, 15:551-8, 1972.

- Differences in responding to auditory verbal materials among aphasic patients. Acta Sym., 1:1-17, 1974. 
- Effects of task difficulty on the sentence comprehension performance of aphasic subjects. J. Com. Dis., $9: 167-73,1976$.

and LOMMEL, M. Perception of sequences of visual temporal and auditory spatial stimuli by aphasic, right hemisphere damaged, and non-brain damaged subjects. J. Com. Dis., 7:155-69, 1974.

BRUNING, J. L. and KINTZ, B. L. Computational Handbook of Statistics. Glenview: Scott Foresman \& Company, 1968.

BUCK, M. Dysphasia: Professional Guidance for the Family and Patient. Englewood Cliffs: Prentice-Hall, 1968.

CARHART, R. and PORTER, L. Audiometric configuration and prediction of threshold for spondees. JSHR, 14:486-95, 1971.

CERMAK, L. S. and MOREINES, J. Verbal retention Ueficits in aphasic and amnestic patients. Brain and Lang., 3:16-27, 1976.

CORLEW, M. M. and NATION, J. E., Characteristics of visual stimuli and naming performance in aphasic adults. Cortex, $11: 186-91,1975$.

DARLEY, F. L., SHERMAN, D. and SIEGEL, G. M. Scaling of abstraction level of single words. JSHR, 2:161-7, 1959.

EBBIN, J. B. and EDWARDS, A. E. Speech sound discrimination of aphasics when intersound interval is varied. JSHR, $10: 120-5,1967$.

EISENSON, J. Adult Aphasia: Assessment and Treatment. Englewood Cliffs: Prentice-Hall, 1973.

ENGMANN, D. L. and BROOKSHIRE, R. H. Effects of simultaneous and successive stimulus presentation on visual discriminations by aphasic patients. JSHR, 13:369-81, 1970.

FILBY, Y., EDWARDS, A. E. and SEACAT, G.F. Word length, frequency and similarity in the discrimination behavior of aphasics. JSHR, 6:255-61, 1963. 
GARDNER, H., ALBERT, M. L., and WEINTRAUB, S. Comprehending a word: the influence of speed and redundancy on auditory comprehension in aphasia. Cortex, 11:155-62, 1975.

GOLDSTEIN, K. Language and Language Disturbances. New York: Grune \& Stratton, 1948.

GOODGLASS, H. Studies on the grammar of aphasics. In H. Goodglass and S. Blumstein (Eds.) Psycholinguistics and A phasia. Baltimore: Johns Hopkins University Press, 1973.

BARTON, M. I. and KAPLAN, E. F. Sensory modality and object-naming in aphasia. JSHR, 11:488-96, 1968.

GREEN, E. and BOLLER, F. Features of auditory comprehension in severely impaired aphasics. Cortex, 10:133-45, 1974.

HELMICK, J. W. and WIPPLINGER, M. Effects of stiınulus repetition on the naming behavior of an aphasic adult: a clinical report. J. Com. Dis., 8:23-9, 1975.

HOLLAND, A. L. and SONDERMAN, J. C. Effects of a program based on the Token Test for teaching comprehensive skills to aphasics. JSHR, 17:589-98, 1974.

JENKINS, J. J., JIMĒNEZ-PABŌN, E., SHAW, R. E., and SEFER, J.E. Schuell's Aphasia in Adults; Diagnosis, Prognosis and Treatment. San Francisco: Harper \& Row Publishers, 1975.

LILES, B. Z. and BROOKSHIRE, R. H. The effects of pause time on the auditory comprehension of aphasic subjects. J. Com. Dis., 8:221-35, 1975.

McDEARMON, J.R. and POTTER, R. E. The use of representational prompts in aphasia therapy. J. Com. Dis., 8:199-206, 1975.

MARSHALL, R. C. Clinician Controlled Auditory Stimulation for Aphasic Adults. Tigard: C. C. Publications, Inc., 1978.

and KING, P. S. Effects of fatigue produced by isokinetic exercise on the communication ability of aphasic adults. JSHR, 16:222-30, 1973. 
, and THISTLETHWAITE, N. Verbal and nonverbal alerters: effects on auditory comprehension of aphasic subjects. Unpublished manuscript, 1977.

TOMPKINS, C. A. and PHILLIPS, D. S. Morning and afternoon scheduling: effects on communicative ability of aphasic subjects. At press, 1978.

and WATTS, M. T. Relaxation training: effects on the communicative ability of aphasic adults. Arch. Phys. Med. Rehab., 57:474-7, 1976.

MARTIN, B. R. Communicative Aids for the Adult Aphasic. Springfield: Charles C. Thomas, 1962.

PIZZAMIGLIO, L. and APPICCIAFUOCO, A. Semantic Comprehension in aphasia. J. Com. Dis., 3:280-8, 1971 .

and ROBERTS, M. Writing in aphasia: a learning study. Cortex, 3:250-7, 1967.

PODRAZA, B. L. and DARLEY, F. L. Effect of auditory prestimulation on naming in aphasia. JSHR, 20:669-83, 1977.

PORCH, B. E. Porch Index of Communicative Ability; Adminis tration, Scoring and Interpretation. Palo Alto: Consulting Psychologists Press, 1973.

ROLNICK, M. and HOOPS, H. R. Aphasia as seen by the aphasic. JSHD, $34: 48-53,1969$.

SCHUELL, H. M. Auditory impairment in aphasia: significance of retraining techniques. JSD, 18:14-21, 1953a.

Aphasic difficulties understanding the spoken language. Neurology, 3:176-84, 1953b.

- Clinical observations on aphasia. Neurology, $\dot{4}: 179-89,1954$.

- Clinical symptoms of aphasia. In L. F. Sies (Ed.) Aphasia Theory and Therapy: Selected Lectures and Papers of Hildred Schuell. Baltimore: University Park Press, 1974. 
, JENKINS, J. J. and LANDIS, L. Relationship

between auditory comprehension and word frequency in aphasia. J $\underline{\text { SHR }}, 4: 30-6,1961$.

, JENKINS, J. J. and JIMENEZ-PABŌN, E. Aphasia in Adults. New York: Harper and Row, 1964.

SHEEHAN, J.G., ASELTINE, S. and EDWARDS, A. E. Aphasic comprehension of time spacing. JSHR, 16:650-7, 1973.

SHEWAN, C. M. and CANTER, G. J. Effects of vocabulary, syntax and sentence length on auditory comprehension in aphasic patients. Cortex, 7:209-26, 1971 .

SIEGEL, G. M. Dysphasic speech responses to visual word stimuli. JSHR, 2:152-60, 1959 .

SIEGEL, S. Nonparametric Statistics for the Behavioral Sciences. New York: McGraw-Hill Book Company, 1956.

SIEGENTHA LER, B. M. and GOLDSTEIN, J. Auditory and visual figure-background perception by adult aphasics. J. Com. Dis., $1: 152-8,1967$.

STOICHEFF, M. L. Motivating instructions and language performance of dysphasic subjects. JSHR, 3:75-85, 1960.

SWINNEY, D. A. and TAYLOR, O. L. Short-term memory recognition search in aphasics. JSHR, 14:578-88, 1971.

TOUBBEH, J. I. Clinical observations on adult aphasia. J. Com. Dis., 2:57-68, 1969.

WEIDNER, W. E. and LASKY, E. Z. The interaction of rate and complexity of stimulus on the performance of adult aphasia subjects. Brain and Lang., 3:34-40, 1976.

WEIGL, E. On the problem of cortical syndromes: experimental studies. In M. L. Simmel (Ed.) The Reach of Mind: Essays in Memory of Kurt Goldstein. New York: Springer Publishing Company, 1968. 
WEIGL, E. and BIERWISCH, M. Neuropsychology and linguistics: topics of common research. In H. Goodglass and $\mathrm{S}$. Blumstein (Eds.) Psycholinguistics and Aphasia. Baltimore: Johns Hopkins University Press, 1973.

WEIGEL-CRUMP C. and KOENIGSKNECHT, R. A. Tapping the Lexical store of the adult aphasic: analysis of the improvement made in word retrieval skills. Cortex, 9:411-8, 1973.

WEINSTEIN, S. Experimental analysis of an attempt to improve speech in cases of expressive aphasia. Neurology, 9:632-5, 1959.

WEPMAN, J. M. Aphasia therapy: a New look. JSHD, 37:203-14, 1972.

WERTZ, R. T. and PORCH, B. E. Effects of masking noise on the verbal performance of adult aphasics. Cortex, 6:399$409,1970$.

WIIG, E. H. and GLOBUS, D. Aphasic word identification as a function of logical relationship and association strength. JSHR, 14:195-204, 1971 . 


\section{APPENDIX A}

\section{SUBJECT CHARACTERISTICS}

\begin{tabular}{|c|c|c|c|c|c|}
\hline SUBJECT & GROUP & $\begin{array}{l}\text { CHRONO- } \\
\text { LOGICAL } \\
\text { AGE } \\
\end{array}$ & SEX & $\begin{array}{c}\text { MONTHS } \\
\text { POST } \\
\text { ONSET } \\
\end{array}$ & $\begin{array}{c}\text { OVERALL } \\
\text { PICA } \\
\text { SCORE } \\
\end{array}$ \\
\hline A & 1 & 78 & $M$ & 4 & 8.86 \\
\hline B & 1 & 60 & $M$ & 10 & 8.86 \\
\hline $\mathrm{C}$ & 1 & 58 & M & 4 & 7.84 \\
\hline $\mathrm{D}$ & 1 & 66 & $F$ & 2 & 7.75 \\
\hline $\mathrm{E}$ & 1 & 64 & M & 3 & 8.69 \\
\hline$F$ & 2 & 58 & $M$ & 4 & 10.04 \\
\hline G & 2 & 74 & M & 2 & 6.17 \\
\hline $\mathrm{H}$ & 2 & 55 & $M$ & 2 & 8.19 \\
\hline I & 2 & 68 & $F$ & 2 & 9.27 \\
\hline$J$ & 2 & 52 & $M$ & 4 & 6.17 \\
\hline
\end{tabular}




\section{APPENDIX B}

SAMPLE EASY AND DIFFICULT ITEMS

\section{EASY ITEMS}

1. Target Picture: Train

\begin{tabular}{|c|c|}
\hline Distractors: & Door \\
\hline & Saw \\
\hline
\end{tabular}

2. Target Picture: Toothpaste

$\begin{array}{lll}\text { Distractors: } & \text { Sweater } & \text { Calendar } \\ & \text { Pumpkin } & \text { Grandfather } \\ & \text { Chicken } & \end{array}$

3. Target Picture: Girl

$\begin{array}{rll}\text { Distractors: } & \text { Kite } & \text { Nose } \\ \text { Bowl } & \text { Hat } \\ & \text { Pen }\end{array}$

\section{DIFFICULT ITEMS}

1. Target Picture: Garage

Distractors: Bedroom Living Room

Kitchen Bathroom

Closet

2. Target Picture: Carrots
Distractors: Peas
Potatoes
Corn
Tomatoes
Celery

3. Target Picture: Pliers

Distractors: Hatchet Saw

Hammer Screwdriver

Wrench 
SCORESHEE'T

NAME:

AGE: DATES:

PICA OA SCORE: TIMES:

ONSET DATE: FIRST:

$\mathrm{AM}$

PM

SCREENING: Presample: $P$ NP Hearing: $P$ NP Visual: $P$ NP Presample

Directions: Look at all the pictures, then point to the picture I name (demonstrate).

1. Stove 2. Bow1 3. Jar 4. Chair 5. Pipe

Primary sample

Directions: Do the same thing with the next group of pictures. Look at all the pictures and point to the picture I name.
1. Train
2. Toothpaste
21. Grandfather
3. Girl
4. Garage
5. Coffee pot
6. Carrots
7. Highway
8. Pliers
9. Orange
10. Dishwasher
22. Farmer
23. Alligator
24. Spoon
25. Dime
26. Needle
27. Cloud
28. Pin
29. Nest
11. Pear
12. Soap
13. One dollar
14. Log
30. Chair
31. Beetle
32. Ambulance
33. Football
34. Eye
15. Thermometer
35. Mountains
16. Cow
36. Toothbrush
17. Train
37. Hospital
18. Orange
38. Hat
19. Axe
39. Blanket
20. Boy
40. Hospital AM PM

$\underline{A M} \underline{P M}$ 
APPENDIX D

RAW SCORES, CORRECT/INCORRECT

\begin{tabular}{c|c|ccc|ccc}
\hline \multicolumn{2}{c|}{} & \multicolumn{3}{c}{ AM } & \multicolumn{3}{c}{ PM } \\
\hline SUBJECT & GROUP & $\mathrm{E}$ & $\mathrm{D}$ & $\mathrm{T}$ & $\mathrm{E}$ & $\mathrm{D}$ & $\mathrm{T}$ \\
\hline $\mathrm{A}$ & 1 & 19 & 17 & 36 & 20 & 18 & 38 \\
$\mathrm{~B}$ & 1 & 20 & 16 & 36 & 19 & 19 & 38 \\
$\mathrm{C}$ & 1 & 11 & 11 & 22 & 13 & 8 & 21 \\
$\mathrm{D}$ & 1 & 19 & 12 & 31 & 17 & 13 & 30 \\
$\mathrm{E}$ & 1 & 20 & 17 & 37 & 19 & 12 & 31 \\
$\mathrm{~F}$ & 2 & 20 & 18 & 38 & 20 & 17 & 37 \\
$\mathrm{G}$ & 2 & 12 & 9 & 21 & 14 & 5 & 19 \\
$\mathrm{H}$ & 2 & 20 & 14 & 34 & 20 & 14 & 34 \\
$\mathrm{I}$ & 2 & 20 & 18 & 38 & 19 & 19 & 38 \\
$\mathrm{~J}$ & 2 & 12 & 7 & 19 & 12 & 6 & 18 \\
\hline
\end{tabular}


APPENDIX E

SUMS OF RAW SCORES, QUALITATIVE

\begin{tabular}{c|c|cc|ccc|c}
\hline \multicolumn{2}{c}{} & \multicolumn{2}{c}{ EASY } & \multicolumn{2}{c}{ DIF FIC ULT } & \multicolumn{2}{c}{ TOTAL } \\
\hline SUBJECT & GROUP & AM & PM & AM & PM & AM & PM \\
\hline A & 1 & 104 & 110 & 91 & 93 & 195 & 203 \\
B & 1 & 118 & 113 & 92 & 106 & 210 & 219 \\
C & 1 & 59 & 72 & 54 & 46 & 113 & 118 \\
D & 1 & 100 & 91 & 73 & 74 & 173 & 165 \\
E & 1 & 115 & 112 & 89 & 67 & 204 & 179 \\
F & 2 & 115 & 117 & 101 & 96 & 216 & 213 \\
G & 2 & 66 & 74 & 50 & 39 & 116 & 113 \\
H & 2 & 97 & 83 & 76 & 76 & 173 & 159 \\
I & 2 & 101 & 93 & 93 & 93 & 194 & 186 \\
J & 2 & 73 & 73 & 51 & 47 & 124 & 120 \\
\hline
\end{tabular}

